\title{
BLICKDIAGNOSE
}

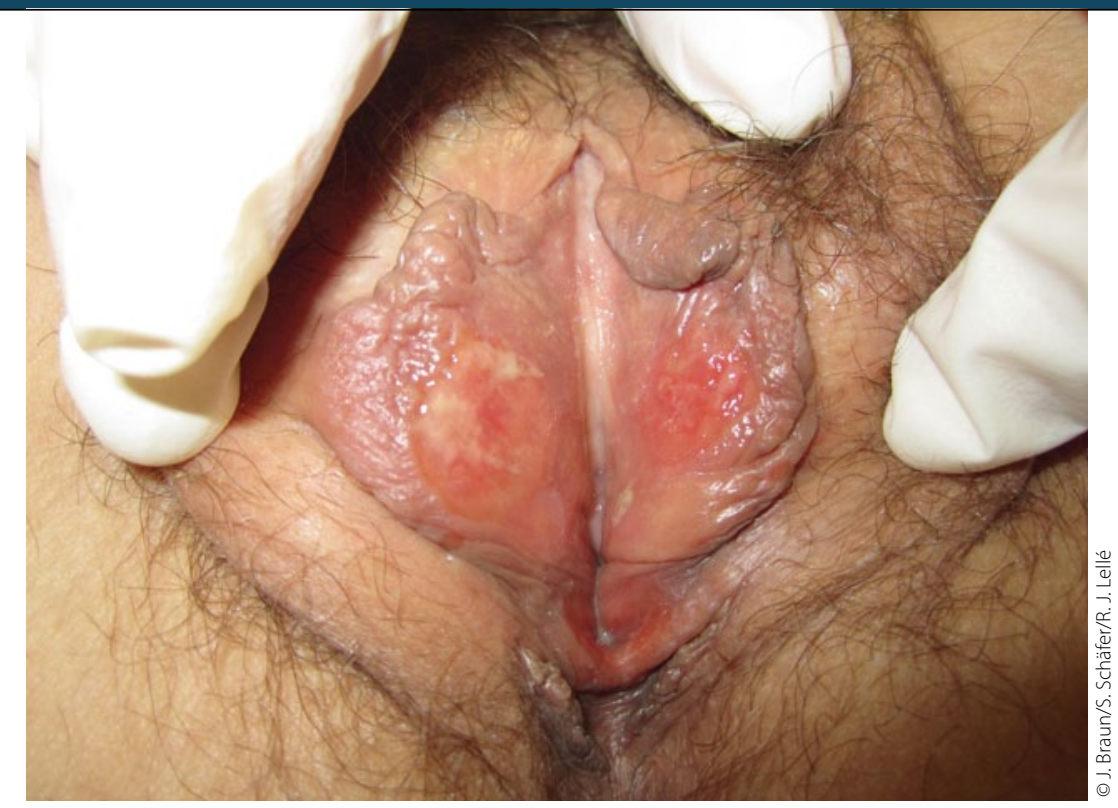

Läsionen an der Vulva, Fieber, Schüttelfrost

\section{Mit dieser Diagnose müssen Sie wieder häufiger rechnen!}

— Die 45-jährige Patientin stellt sich mit brennenden Schmerzen im Vulvabereich vor. Man erkennt flache ulzeröse Defekte an den Labieninnenseiten beidseits sowie an der hinteren Kommissur.

Zweieinhalb Wochen zuvor waren erstmals Vulvabeschwerden aufgetreten. Zwei Tage lang litt die Patientin unter Schüttelfrost und Fieber. Zunächst war an eine Herpessimplex-Infektion gedacht worden. Die Behandlung mit Acyclovir brachte jedoch keine Besserung. Letztlich wurde die Diagnose einer Lues venerea durch serologischen Antikörpernachweis gestellt.

Demnach handelt es sich bei der dargestellten Vulvaläsion um den Primäraffekt einer Lues. Dieser wird auch als „Ulcus durum" bezeichnet, da der Geschwürsrand häufig induriert ist, was allerdings hier nicht der Fall war. Bei rechtzeitiger Erkennung im Primärstadium ist die Therapie durch Penicillin hocheffektiv.
Lues-Erkrankungen sind anonymisiert meldepflichtig. Das zuständige Robert Koch-Institut (www.rki.de) berichtet über 3398 gemeldete Fälle im Jahre 2011. Dies entspricht einem erheblichen Anstieg im Vergleich zum Vorjahr von $22 \%$ !

Keywords: primary syphilis

- Dr. med. Janina Braun, Dr. med. Sebastian D. Schäfer, Univ.-Prof. Dr. med. Ralph J. Lellé, MIAC, UniversitätsFrauenklinik Münster, Albert-Schweitzer-Campus 1, D-48149 Münster

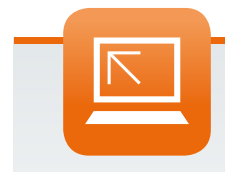

Weitere Infos auf springermedizin.de

Weitere Fälle unserer Leser finden Sie im Internet unter: - www.springermedizin.de/blickdiagnose 